\title{
IL-1 inhibition in Muckle-Wells-Syndrome: withdrawal resulting in rapid deterioration of hearing loss
}

\author{
S Hansmann ${ }^{*}$, K Ambjoernsen$^{2}$, A Koitschev $^{3}$, SM Benseler ${ }^{1}$, JB Kuemmerle-Deschner ${ }^{1}$ \\ From 8th International Congress of Familial Mediterranean Fever and Systemic Autoinflammatory Diseases \\ Dresden, Germany. 30 September - 3 October 2015
}

\begin{abstract}
Introduction
Muckle-Wells syndrome (MWS), a phenotype within the spectrum of cryopyrine-associated periodic syndrome (CAPS) is characterized by excessive IL-1 release resulting in chronic systemic and organ-specific inflammation including sensorineural hearing loss. During continuous anti-IL-1-therapy clinical symptoms are controlled and hearing loss remains stable. Limited data exists about discontinuation of IL-1-inhibition during the course of disease.
\end{abstract}

\section{Objective}

To report the case of a MWS patient, with sudden deterioration of hearing loss due to discontinuation of anti-IL1-therapy and improvement of hearing after re-therapy.

\section{Case report}

A 29 year old female patient was diagnosed with MWS at age 17 . Her left ear had been deaf since early childhood. The patient experienced arthralgia, exanthema, fatigue and progressive hearing loss of the right ear during childhood. Anti-IL-1-therapy with Anakinra was started 4 years after diagnosis. In 2007, she was switched to Canakinumab resulting in complete resolution of exanthema and arthralgia and improved fatigue. Hearing loss was stable during therapy as documented by frequent high frequency pure tone assessments (HFPTA).

When she became pregnant, MWS treatment was changed from Canakinumab to Anakinra as suggested by the safety profile. The patient gave birth to a healthy boy, who has a CAPS mutation.

'University Hospital Tuebingen, University Children's Hospital Tübingen, Tuebingen, Germany

Full list of author information is available at the end of the article
The patient decided to discontinue IL-1-inhibition while breast-feeding. After four months off anti-IL-1therapy, her hearing had markedly deteriorated: HFPTA demonstrated a decrease of $20-30 \mathrm{~dB}$ in frequencies most relevant for speech discrimination, a substantially impairment for a unilateral deaf patient. The patient decided to stop breast-feeding and Canakinumab therapy was immediately re-initiated. Two months later improved hearing was documented with 5-10 dB but still 10-25 dB less than before discontinuation.

\section{Conclusion}

Long-term IL-1-inhibition prevents decline of hearing ability in CAPS. Withdrawal of treatment may result in rapid and marked hearing loss. An early restart of antiIL-1-therapy may partially reverse hearing loss. This indicates a window of opportunity for reversal of hearing loss by IL-1-inhibition. To our knowledge, this is the first case in which such a close connection between IL-1-inhibition and hearing ability in MWS has been documented. This case report shows the importance of continuation of anti-IL-1-therapy during pregnancy and breast-feeding to reduce the risk of sequel.

\section{Consent to publish}

Written informed consent for publication of their clinical details was obtained from the patient/parent/guardian/ relative of the patient.

\footnotetext{
Authors' details

${ }^{1}$ University Hospital Tuebingen, University Children's Hospital Tübingen, Tuebingen, Germany. ${ }^{2}$ University Hospital Tuebingen, University Department of Otolaryngology, Tuebingen, Germany. ${ }^{3}$ Hospital Stuttgart, Department of Otorhinolaryngology, Stuttgart, Germany.
} 
- Convenient online submission

- Thorough peer review

- No space constraints or color figure charges

- Immediate publication on acceptance

- Inclusion in PubMed, CAS, Scopus and Google Scholar

- Research which is freely available for redistribution 